\title{
Unmanned Spacecrafts and Space Drones as the Challenges for Space Law
}

\author{
Svitlana Vyshnovetska \\ Doctor of Law, Professor, National Aviation University (Kyiv, Ukraine) \\ E-mail:vyshnsv@ukr.net \\ https://orcid.org/0000-0001-8482-7942 \\ Volodymyr Melnyk
}

Ph.D. in Law, Associate Professor, Kyiv Institute of Intellectual Property and Law of the National University “Odessa Academy of Law” (Kyiv, Ukraine)

E-mail: melnik.v.p@gmail.com

https://orcid.org/0000-0002-9013-6504

\begin{abstract}
In the article, the authors considered the challenges for space law, which are created by the intensive development of production technologies of unmanned spacecrafts and space drones, as well as their use in the space industry. The authors clarified the term "space object", which is used in the Space Law. This helped reveal the difference between the terms "unmanned spacecrafts" and "space drones", which are synonymous in the Air Law. The authors investigated the basics of the space law and proved that in the existing formulations, the space law is not able to regulate the modern space exploration. Based on the study, the authors proposed: (1) to consolidate the influence of public organizations created in the space industry and specializing in the space exploration in the space law; (2) to change approaches to space law; space law should be considered as an effective regulator capable of ensuring the sustainable development of the mankind;. (3) under the space law, to create a holistic concept for using all types of space object on the Low Earth Orbit.
\end{abstract}

Keywords: space object, unmanned spacecrafts, space law, space drones, U-space, air law, Low Earth Orbit

Received: August 27, 2019; accepted: September 28, 2019

Philosophy and Cosmology, Volume 24, 2020: 39-47.

https://doi.org/10.29202/phil-cosm/24/4

\section{Introduction}

Mikko Huttunen discloses the issues related to integration of civil unmanned aircraft systems (drones) into airspace in the article "The U-Space Concept". These are problems relating primarily to safety, traffic management, privacy, and law enforcement. To solve them

(C) Vyshnovetska, Svitlana, 2020

(C) Melnyk, Volodymyr, 2020 
the European regulatory bodies have come up with a new concept: U-space. Huttunen proves in his study that U-space is not merely a legal but also a technological concept, and it is as much a public as it is a private effort (Huttunen, 2019).

The Air Law is governed by various laws and regulations (Khomiachenko, 2018), two of which are the determining documents:

1. The Convention on International Civil Aviation. It was first adopted in 1944. The sixth, latest edition was published in 2006. As of March 2019, the Chicago Convention had 193 state parties

2. Standards and Recommended Practices (SARPs) developed by the International Civil Aviation Organization (ICAO) (Standards, 2019). Unlike the Chicago Convention, SARPs have no legal force. They are published by ICAO in the form of Annexes to Chicago Convention and are advisory in nature.

International non-governmental associations play the important role in organizing and coordinating the air transport industry. They are the driving force that stimulates the continuous excellence of defining laws and regulations of the Air Law. For example, the International Air Transport Association (IATA). The IATA was established in 1945 and currently represents "the prime vehicle for inter-airline cooperation in promoting safe, reliable, secure and economical air services - for the benefit of the world's consumers" (International, 2019). Today it has some 290 members from 120 nations in every part of the globe.

The existing organizational structure and legal support of the airspace up to the last decade made it possible to provide reliable and secure air service. The advent of unmanned aircraft systems (or drones) and their intensive development have created three major problems for the Air Law (Huttunen, 2019):

1. The price of drones varies from cheap to expensive. These devices can be toys that are used by teenagers and adults without any training, and they can be commercial systems that are managed by specialists.

2. Due to their small size and low retail price, many drones are not equipped like a transponder, which provides their safety among other aircraft. In addition, drones usually operate at low altitude, which is classified as uncontrolled. At this altitude, there is a great risk of collisions between drones and people, structures, and other aircraft. This risk makes drones potentially dangerous to privacy and security.

3. According to the definition, drones do not have a pilot on the board. Therefore, drones face difficulties with the VFR / IFR distinction, and their capability to follow established avoidance procedures is also limited.

There are some attempts to solve the problem in the aviation industry in different ways. For example, the creation and implementation in practice the U-Space concept. The creation of the concept of "U-space" was first proposed at the European 2016 High Level Conference on Drones. In the legal field, U-space was legalized last year. This is above all, Notice of Proposed Amendment 2017-05 (A) (Notice, 2017) and Notice of Proposed Amendment 2017-05 (B) (Notice, 2017), as well as in Opinion No 01/2018 (Opinion, 2018) and other regulations (Huttunen, 2019). A full review of the U-Space concept, as well as the features of its implementation in practice are outlined by Mikko Huttunen (Huttunen, 2019).

Integration of civil unmanned aircraft systems into the airspace goes through the first stages only. On its way, there are many problems, both scientific and technical, and those associated with changes in international and national laws. Mikko Huttunen concludes that 
"the design of the legal framework is inappropriate for drones in numerous ways" (Huttunen, 2019: 87). The concept of U-Space at present represents only fragments that as a whole do not work in any state yet. The full implementation of the U-Space concept is expected by 2027.

In this article, we will expand the perception of the intensive development of unmanned aircraft systems to the space industry. We explore the challenges for space law that are created by the intense development of unmanned spacecrafts and space drones.

\section{Modern technologies of development of unmanned spacecrafts and space drones}

Currently, space exploration is carried out in three main directions. These are the earthbased observations, airborne and orbital telescopes, probes and fly-by spacecraft, orbiters, Landers, rovers, and sample return. As Chris Barrett wrote back in 2000, "We now know of 66 moons in our own Solar System, one with an atmosphere, 16 with water ice or oceans, and 5 with both. In addition, we now know of 20 extra-solar planets" (Barrett, 2000).

New knowledge about the Universe, discover new resources that amaze with their inexhaustibility and power. The search for knowledge and inexhaustible sources of energy makes the mankind expand its sphere of activity. The first settlements on the Moon and Mars are planned already in the 2030s. They open up new prospects for the involvement of space resources in human-organized cycles of matter, energy, and information. For example, a study by Evgeny Slyuta proves the reality of gas production on the Moon and its use by humans (Slyuta, 2017).

In the aircraft industry, the terms "unmanned aircraft systems" and "drones" are often used synonymously. Regulatory documents of the Air Law evidence of this (Notice, 2017; Opinion, 2018). The space industry terminology has not been so well-established and defined. The reason is the lack of perfection of space law. Let us consider the classification of the products of the space industry, with the help of which humanity masters the near space. The reason is the lack of improvement of the space law. Let us consider the classification of the products of the space industry, with the help of which the humanity explores the near space.

In the space law, the term "space object" is used. "Convention on Registration of Objects Launched into Outer Space" gives the following definition: the term "space object" includes component parts of a space object as well as its launch vehicle and parts there of (Convention, 1974). The Registration Convention was adopted in 1974 and entered into the force in 1976. Since then, no clarifications have been made. Victoria Rybachok in her study "The Term Space Object and its Legal Status" pointed out the legal conflicts caused by the discrepancy between the meanings of the term "space object" and modern realities. Rybachok made strong arguments for the need to clarify the term "space object" in the space law (Rybachok, 2018).

Let us specify the term "space object".

On the website of the United Nations Office for Outer Space Affairs we find such a record: "To date over $88 \%$ of all satellites, probes, landers, crewed spacecraft and space station flight elements launched into Earth orbit or beyond have been registered with the SecretaryGeneral" (United Nations, 2019). In the space law, the classification "space object" is not specified. We will take as a basis the classification given at the official website of the key authority, which is the legal authority of the international space law.

The information on website of the United Nations Office for Outer Space Affairs allows us to clarify the term "space object". These are satellites, probes, landers, crewed spacecraft and space station flight elements launched into Earth orbit or beyond. 
In the space industry, the established classification concerns only man crewed spacecraft. Although, we emphasize, this classification is not enshrined in the space law. Man crewed spacecraft includes space capsules, spaceplanes, and space stations, on board of which the full human life is provided. Consequently, the remaining categories such as "satellites, probes, landers, and spacecraft" we should refer to "unmanned spacecrafts".

Uncrewed spacecrafts - are spaceships without people on board, used for robotic spaceflight. Uncrewed spacecrafts have different levels of autonomy from human participation. They may be remote controlled, remote guided or even autonomous, meaning they have a pre-programmed list of operations, which they will execute unless otherwise instructed. The official website of NASA provides a classification of Uncrewed spacecrafts. It is not unified and mandatory for space agencies of other states. Although, for example, the Department of Space of Indian Space Research Organization uses roughly the same classification of uncrewed spacecrafts (List of Spacecrafts, 2019). NASA identifies eight broad classes of robotic spacecraft according to the missions the spacecraft are intended to perform (Spacecraft Classification, 2003):

1. Flyby spacecraft.

2. Orbiter spacecraft.

3. Atmospheric spacecraft.

4. Lander spacecraft.

5. Rover spacecraft.

6. Penetrator spacecraft.

7. Observatory spacecraft.

8. Communications spacecraft

We should note that the existing uncrewed spacecrafts classification does not use the term "space drones". A possible reason is that in 2003, the type of "space drones" was not so common and in demand in the space industry.

Mostafa Hassanalian and the co-authors explore the emergence and evolution of space drones in the space industry. Mostafa Hassanalian is considered to be one of the key experts in the field of space drones research. In the studies of Mostafa Hassanalian and his coauthors, we meet the classification of space drones for the first time (Hassanalian et al., 2018; Hassanalian et al., 2018a). In the classification of space drones, Hassanalian is based on the research by Chris Barrett, who singled out in the emerging "new types of planetary exploration vehicles - aerobots and hydrobots" (Barrett, 2000). Hassanalian et al. gave the extended classification of aerobots and hydrobots. "Aerobots include robotic atmospheric vehicles, such as drones, lighter-than-atmosphere vehicles, and suborbital ballistic hoppers which are applied for exploration of planetary atmospheres. Hydrobots include gravity-melt lander vehicles, submersible hydrodynamic robotic vehicles, and submersible probes which are applied for planetary ocean exploration" (Hassanalian et al., 2018a).

Hassanalian et al proposed a technique, which distinguishes two main types of drones including fixed and rotary wings that have been considered for planetary exploration. Although, as the authors admit, "nowadays there are more configurations for planetary exploration, such as balloons, airships, gliders, fixed wings, helicopters, cyclocopters, VTOLs, tilt-rotors, rotary wings, and flapping wings" (Hassanalian et al., 2018a). Such a variety of configurations of space drones is not accidental. Mostafa Hassanalian believes space drones are more efficient than the orbitals and rovers. Drones can perform research that, for technical reasons, other classes of robotic spacecraft cannot do. Researches with 
drones will greatly expand the knowledge of a planetary science. Therefore, the development of space drones in the space industry is more promising.

Thus, we can draw the following intermediate conclusions of our study:-

1. The terminology used in the space law does not correspond to the current level development of technologies in the space industry. This leads to the legal conflicts. In particular, the term "space object", which is used in the space law, does not allow to classify the space technology and consider its use in the legal field, as it is done in the air law.

2. We have clarified the classification of the term "space object" and concluded that in the space law, the terms "unmanned spacecrafts" and "space drones" are not synonymous. Currently, the United Nations Office for Outer Space Affairs, as the legal body of the international space law, has not approved the standards to classify uncrewed spacecrafts. In NASA's classification of robotic spaceflights, the term "space drones" is not used.

3. Space drones are the most efficient and promising types of unmanned spacecrafts. The type of "space drones" is considered as a priority in the study of planets and other space objects. However, in the space law, this type of space technology is not mentioned anywhere.

In order to understand the reason for the conservatism of the space law and offer the own clarifications in the space law related to the use of space drones, we must consider the basics of the current space law.

\section{The modern basics of the space law}

Let us consider the basics of the modern space law. The treaties commonly referred to as the "five United Nations treaties on outer space" are (United Nations, 2002):

1. Treaty on Principles Governing the Activities of States in the Exploration and Use of Outer Space, including the Moon and Other Celestial Bodies (General Assembly resolution 2222 (XXI), annex) - adopted on 19 December 1966, opened for signature on 27 January 1967, entered into force on 10 October 1967.

2. Agreement on the Rescue of Astronauts, the Return of Astronauts and the Return of Objects Launched into Outer Space (resolution 2345 (XXII), annex) — adopted on 19 December 1967, opened for signature on 22 April 1968, entered into force on 3 December 1968.

3. Convention on International Liability for Damage Caused by Space Objects (resolution 2777 (XXVI), annex) - adopted on 29 November 1971, opened for signature on 29 March 1972, entered into force on 1 September 1972.

4. Convention on Registration of Objects Launched into Outer Space (resolution 3235 (XXIX), annex) - adopted on 12 November 1974, opened for signature on 14 January 1975, entered into force on 15 September 1976.

5. Agreement Governing the Activities of States on the Moon and Other Celestial Bodies (resolution 34/68, annex) — adopted on 5 December 1979, opened for signature on 18 December 1979, entered into force on 11 July 1984.

Along with five General Assembly resolutions, the Declaration of Legal Principles forms the basis of the international law (United Nations, 2002). 
It is obvious, the basis of the space law is formed by the laws and principles that were adopted at the beginning of the era of human space exploration. In contrast to the air law, the foundations of the space law are not reviewed. It reduces the effectiveness of the space law in some degree. In fact, space exploration is carried out outside the law.

In this regard, the study by Valentyn Halunko deserves attention. Halunko's considered the current trends in the development of space law. Trade regulation factors in outer space, as well as the legal aspects of the militarization of outer space and space debris have been clarified. The tasks of the space law, considered by Halunko, such as: standardization of legal space terms, approval of private space law, stimulation of private capital involvement in space programs, development of the theory of the right to use space bodies, regulation of the rights and legitimate interests of space tourists, development of sanctions agreed by the world community for violation of space law, subjects and procedures for their application deserve special attention (Halunko, 2019).

Larysa Soroka and Kseniia Kurkova investigated the specifics of the legal regulation of the use and development of artificial intelligence for the space area. The authors have proved the need of adoption of a legal instrument under the auspices of the United Nations, which would cover the creation of a law enforcement international agency monitoring artificial intelligence the observation of basic human rights in space technologies (Soroka \& Kurkova, 2019).

The study of the foundations of the space law, as well as the contemporary researches in the space law, leads us to the following conclusions:

1. The fundamentals of the space law do not correspond to the modern challenges of the space industry. If the fundamentals of the air law are periodically reviewed and improved, taking into account new advances in aviation science and technology, the fundamentals of the space law have never changed since they were adopted.

2. The space industry is rapidly developing. Projects of development of the Moon and Mars are coming to the final stage of implementation. Along with the government projects, private investors and companies take an active part in space exploration. The foundations of the space law do not take into account the peculiarities of the new reality.

3. If we compare the features of the development of the air law and the space law, then the absence of a consistent policy of development of the space law is noteworthy. In our view, the United Nations Office for Outer Space Affairs is failing in its responsibilities. The reason, perhaps, is not so much in it, as in the absence of authoritative and powerful in the degree of influence of non-governmental organizations, such as the International Civil Aviation Organization (ICAO), International Air Transport Association (IATA) and others. In the space industry, the non-governmental international organizations have not yet achieved the degree of influence that they have had in the aviation industry. It is for this reason that the United Nations Office for Outer Space Affairs takes a passive position and does not perform its key statutory functions.

4. The modern space law does not regulate space exploration. In fact, many human actions in space go beyond the existing space law. Case in point, using space drones. This term is not used in the space law, although in the prospects of space exploration this type of unmanned spacecrafts is the key one. 


\section{Conclusions}

In conclusion of our study, we will return to the U-Space Concept and its legal regulation of the air law. Mikko Huttunen's research reveals to us not only the relevance of the U-Space, but also the difficulties of its implementation in practice. The main difficulty lies in changing the international law and national legislations (Huttunen, 2019). This is a complex and timeconsuming process that occurs under the influence of new technologies embodied in the everyday life of a person. However, this process ensures the order and safety of airspace use.

Modern cosmological models affirm man in the role of cosmic force (Bazaluk, 2015; Kastrup, 2018). Intensive development of the space industry makes space exploration plans real. With our research, we want to draw attention to the difficulties associated with any changes in space law. Bearing in mind that outer space is a res communis area (i.e. outside the jurisdiction of any State), the consideration of the concept of 'exploration and use' under the guidance of the sustainable development principle requires a special approach. This issue was first raised in a study by Orsola Greco (Greco, 2019). The concept of 'exploration and use', in which Greco examines the threats posed by small satellites to the sustainability of the Low Earth Orbit environment, is similar in content to the threats that the U-Space Concept is trying to prevent. However, in terms of complexity of implementation and consequences, these threats are incomparably more complex.

All human activity in outer space should be determined and regulated by the space law. Without exception, all the leading states of the world realize their ambitions in space. Therefore, the lack of the term "space drones" in the space law, which can be technologically used for both space exploration and military purposes, poses threats to security on the Earth. The use of space drones needs strict regulation. As practice shows, the creation of unmanned spacecrafts in most cases involves dual use: for peaceful and military purposes. The space law is the only and key regulator that defines and protects the interests of all mankind. For this reason, we offer:

1. The space industry needs powerful non-governmental international associations capable of exerting pressure on the United Nations Office for Outer Space Affairs and national space agencies. It is necessary to strengthen the influence and secure in the space law the determining role of public organizations created in the space industry and specializing in the space exploration. These organizations should become the necessary driving force for the development of space law.

2. It is necessary to change the approaches to the space law. The space law should be considered as an effective regulator capable of ensuring the sustainable development of mankind. Its effectiveness should be significantly higher and take into account all the changes that occur in the space industry as a result of the introduction of new technologies.

Within the framework of the space law, it is necessary to create a holistic concept of using all types of space objects on the Low Earth Orbit. It will ensure the legal regulation of the use of outer space by the states and private corporations.

\section{References}

Barrett, Chris. (2000) Aerobots and Hydrobots for Planetary Exploration. NASA STI/Recon Technical Report N, 99. https://doi.org/10.2514/6.2000-633 
Bazaluk, Oleg. (2015) The Basic Postulates of the Universal Evolution Model "Evolving Matter". Philosophy and Cosmology 2015 (Vol. 14), 11-20.

Convention on Registration of Objects Launched into Outer Space. (1974) General Assembly, Resolution 3235 (XXIX), 12 November 1974. https://www.unoosa.org/oosa/en/ ourwork/spacelaw/treaties/registration-convention.html

Convention on International Civil Aviation. (2006). https://www.icao.int/publications/ Documents/7300_9ed.pdf

Greco, Orsola. (2019) Small Satellites: A Threat for the Future Sustainability of Outer Space Exploration? Air and Space Law, Volume 44, 91-110

Halunko, Valentyn. (2019) Space Law: the Present and the Future. Advanced Space Law, Volume 3, 30-47. https://doi.org/10.29202/asl/2019/3/3

Hassanalian, Mostafa, Devyn Rice, and Abdessattar Abdelkefi. (2018) Evolution of space drones for planetary exploration: A review. Progress in Aerospace Sciences. Volume 97, February, 61-105. https://doi.org/10.1016/j.paerosci.2018.01.003

Hassanalian, Mostafa, Devyn Rice, Stephen Johnstone, and Abdessattar Abdelkefi. (2018a) Planetary exploration by space drones: design and challenges. 2018 Aviation Technology,

Integration, and Operations Conference. https://doi.org/10.2514/6.2018-3027

Huttunen, Mikko. (2019) The U-Space Concept. Air and Space Law, Vol. 44, No. 1, 69-89.

International Air Transport Association (IATA). (2019). https://www.iata.org/Pages/default. aspx

Kastrup, Bernardo. (2018) The Next Paradigm. Future Human Image, Volume 9. https://doi. org/10.29202/fhi/9/4

Khomiachenko, Svitlana. (2018) Use of Airspace by Aircraft: Features of Legal Regulation. Advanced Space Law, Volume 2, 39-43. https://doi.org/10.29202/asl/2018/2/5

List of Spacecrafts. (2019) Department of Space, Indian Space Research Organisation. https://www.isro.gov.in/list-of-spacecrafts

Notice of Proposed Amendment 2017-05 (A). (2017) Introduction of a regulatory framework for the operation of drones. Unmanned aircraft system operations in the open and specific category. European Aviation Safety Agency. https://www.easa.europa.eu/ sites/default/files/dfu/NPA\%202017-05\%20(A)_0.pdf

Notice of Proposed Amendment 2017-05 (B). (2017) Introduction of a regulatory framework for the operation of drones. Unmanned aircraft system operations in the open and specific category. European Aviation Safety Agency. https://www.easa.europa.eu/ sites/default/files/dfu/NPA\%202017-05\%20(B).pdf

Opinion No 01/2018. (2018) Introduction of a regulatory framework for the operation of unmanned aircraft systems in the 'open' and 'specific' categories. European Aviation Safety Agency. https://www.easa.europa.eu/sites/default/files/dfu/Opinion $\% 20$ No\%2001-2018.pdf

Rybachok, Victoria. The Term "Space Object" and its Legal Status. Advanced Space Law, Volume 2, 2018: 44-49. https://doi.org/10.29202/asl/2018/2/6

Slyuta, Evgeny. (2017) Problems of research and mining of gas deposits on the Moon. Mining of Mineral Deposit. 11(4), 117-125. https://doi.org/10.15407/mining11.04.117

Soroka, Larysa, and Kseniia Kurkova. (2019) Artificial Intelligence and Space Technologies: Legal, Ethical and Technological Issues. Advanced Space Law, Volume 3, 131-139. https://doi.org/10.29202/asl/2019/3/11

Spacecraft Classification. NASA, 12.18.03. https://www.nasa.gov/audience/forstudents/ postsecondary/features/F_Spacecraft_Classification.html 
Standards and Recommended Practices (SARPs). (2019) International Civil Aviation Organization (ICAO). https://www.icao.int/safety/safetymanagement/pages/sarps. aspx

United Nations Office for Outer Space Affairs. (2019). https://www.unoosa.org/oosa/en/ spaceobjectregister/index.html

United Nations Treaties and Principles on Outer Space. (2002) United Nations, New York. https://www.unoosa.org/pdf/publications/STSPACE11E.pdf 